\title{
Bioética Global y política
}

\section{Global Bioethics and politics}

\author{
Juan-Ramón Lacadena \\ Departamento de Genética, Faculdade de Biologia, Universidade Complu- \\ tense de Madrid, Madrid, Espanha. \\ jrlgbucm@bio.ucm.es
}

\begin{abstract}
Resumen: Desde el punto de vista de la sociobiología, podría decirse que la especie Homo sapiens ha pasado por diferentes niveles éticos. Así, en un pasado ético la humanidad pasó sucesivamente por los niveles éticos individual, familiar, tribal, social, racial, regional, nacional; sin embargo, podemos ver con esperanza que en el presente ético se manifiesta ya un nivel de humanidad, como lo atestiguan -aunque sea con muchas imperfecciones - la aplicación de los derechos humanos, los movimientos de pacificación y de defensa de la naturaleza, la responsabilidad ante las generaciones futuras etc. En otras palabras, estamos empezando a vivir una Bioética Global hermanada con una Ética de la Responsabilidad, tal como propusieran Van Rensselaer Potter y Hans Jonas, respectivamente. Ambas juntas nos llevan a la utilización política de los principios bioéticos: Bioética Global y Política, que es el objeto de este estudio. En este contexto, se hace especial referencia a la importancia de la "opinión pública" frente a la "opinión publicada" y se presentan de forma resumida los resultados de dos encuestas europeas realizadas en 2003 (Fundación Banco Bilbao Vizcaya Argentaria - BBVA, España) y 2005 (Eurobarómetro) sobre la opinión de los ciudadanos europeos en temas relacionados con la manipulación de embriones humanos y con la biotecnología.
\end{abstract}

Palabras-clave: Bioética Global. Ética de la Responsabilidad. Manipulación de embriones. Biotecnología. Encuesta europea. Eurobarómetro.

\begin{abstract}
From a sociobiological point of view, one may say that human species has been through different ethical levels. From an ethical past mankind has been therefore experiencing individual, familiar, tribal, social, racial, regional, national ethical stages. However, at present moment we can hopefully realize that ethical concerns of mankind - although with intrinsic imperfections - are embodied in the development of human rights, peaceful movements, protection of nature, responsibility towards future generations etc. In other words, we are starting to practice a Global Bioethics in conjunction with an Ethics of Responsibility as proposed respectively by Van Ressenlaer Potter and Hans Jonas. Together they lead to the political use of bioethical princi-
\end{abstract}


ples: Global bioethics and politics, that constitutes the issue of this study. In its context, special attention is given to the importance of "public-opinion" versus "published opinion" and two european public-opinion polls from 2003 (BBVA Foundation Banco Bilbao Vizcaya Argentaria, Spain) and 2005 (Eurobarometer) about issues related to human embryo manipulations and biotechnology are briefly analyzed.

Key words: Global Bioethics. Ethics of Responsibility. Human embryo manipulations. Biotechnology. European opinion. Eurobarometer.

El comportamiento se puede definir como cualquier reacción a cualquier estímulo, incluyendo, por tanto, desde los simples tropismos y taxias hasta los reflejos, instintos, aprendizaje, inteligencia y consciencia, pudiendo admitirse como regla general la existencia de una correlación positiva entre el grado de complejidad de la pauta de comportamiento de los seres vivos y su posición en la escala evolutiva. La ética es una manifestación del comportamiento humano (1).

En la evolución humana, la hominización ocurre cuando el homínido adquiere consciencia de sí mismo y esa capacidad de autorreflexión es una consecuencia evolutiva: el ADN de los homínidos fue adquiriendo la información necesaria para llegar a realizar tan alta función intelectual. El ser humano tiene tres singularidades que le diferencian de cualquier otro ser vivo: es sujeto culto, sujeto religioso y sujeto ético; es decir, como consecuencia de su propio proceso evolutivo, ha adquirido la capacidad genética de utilizar el lenguaje simbólico (sujeto culto), estar abierto a la trascendencia al preguntarse por el origen y el destino del hombre y el sentido de su vida (sujeto religioso) y ser capaz de hacer juicios de valor, distinguir el bien del mal y optar libremente por uno u otro (sujeto ético).

Como señala Dobzhansky, todas las sociedades humanas de las que se tiene conocimiento han tenido códigos éticos o morales más o menos sofisticados. Algunos, quizá, son intrínsecos - genéticos, podría decirse - a la propia naturaleza humana (cuidar la prole, aceptación de la autoridad y respeto paterno etc.), mientras que otros son adquiridos a través del medio cultural (la educación, las normas) y pueden variar con la evolución de las costumbres (2). 


\section{Revista Brasileira de Bioética}

Es evidente que los valores éticos no son hereditarios, sino que, como indicaba Waddington, los seres humanos, como especie biológica, están genéticamente capacitados para ser éticos (3). La evolución no ha prefijado una sola clase de ética en la humanidad, sino que ha hecho a los seres humanos - como especie biológica - capaces de crear, aprender o asimilar diversos tipos de ética, moralidad o juicios de valor. Se puede hablar de una moral o ética hindú, islámica o cristiana y de que el hombre las acepte o las rechace, porque está capacitado para ello, pero no porque esté genéticamente condicionado a una u otra.

El comportamiento moral de las personas resulta de una compleja influencia cultural (herencia cultural) que utiliza o potencia una capacidad genéticamente determinada (herencia biológica). ¿ Tiene esto sentido evolutivo? Posiblemente sí, puesto que se conocen especies animales con ciertas capacidades éticas rudimentarias. Existen algunas pautas de comportamiento animal que, en juicio de valor humano, podrían ser consideradas como éticas o altruistas, mientras que otras podrían estimarse como no éticas o egoístas.

En un contexto biológico pueden distinguirse varios tipos de ética: la ética individual, la ética familiar y la ética de grupo (4). En muchas ocasiones, las conductas éticas de tipo familiar están genéticamente determinadas y sometidas a la acción de la selección natural; por ejemplo, cuando alguno de los progenitores pone en riesgo su vida llamando la atención de un depredador que amenaza a sus crías. El valor evolutivo positivo de este comportamiento radica en que la pérdida de genes determinantes de tal conducta que supondría la muerte del progenitor, se vería compensada por la supervivencia de sus descendientes y con ella la de los posibles genes que ellos llevaran en sus genotipos. Por el contrario, las conductas éticas de grupo no son producto de la evolución biológica, sino de la cultural, puesto que el sacrificio del bien individual al bien colectivo resultaría desventajoso - biológicamente hablando - a los individuos que la practicaran.

Desde el punto de vista de la sociobiología podría decirse que la especie Homo sapiens ha pasado por diferentes niveles éticos. En un pasado ético la humanidad pasó sucesivamente por los niveles éticos individual, familiar, tribal, social, racial, regional, nacional; sin embargo, podemos ver con esperanza que en el presente ético se mani- 
fiesta ya un nivel de humanidad, como lo atestiguan - aunque sea con muchas imperfecciones - la aplicación de los derechos humanos, los movimientos de pacificación y de defensa de la naturaleza, la responsabilidad ante las generaciones futuras etc. En otras palabras, estamos empezando a vivir una Bioética Global hermanada con una Ética de la Responsabilidad, tal como propusieran Van Rensselaer Potter $(5 ; 6)$ y Hans Jonas $(7 ; 8)$, respectivamente. Ambas juntas nos llevan a la utilización política de los principios bioéticos: Bioética Global y Política, que es el objeto de este estudio.

\section{La Bioética Global de Potter}

El 6 de septiembre de 2001, a los noventa años de edad, falleció Van Rensselaer Potter II, considerado por muchos como el padre de la bioética en el sentido de que fue él quien propuso por vez primera en la historia de la civilización humana la utilización del término bioética aplicado a una nueva ciencia de la supervivencia (9) que habría de ser el puente hacia el futuro de la humanidad (10). Con tal ocasión, escribí varios artículos in memoriam $(11 ; 12)$ que utilizaré a continuación.

Como indicaba anteriormente, la primera vez que utilizó Potter el neologismo bioética (bioethics) fue en un artículo aparecido a finales de 1970 y poco tiempo después, en enero de 1971, Potter publicó el primer libro de la historia que llevaba por título el término bioética escrito con el propósito de contribuir al futuro de la especie humana promocionando la formación de una nueva disciplina: la bioética. El justificaba su esfuerzo en el prefacio de la obra diciendo:

"Hay dos culturas - ciencias y humanidades - que parecen incapaces de hablarse una a la otra y si ésta es parte de la razón de que el futuro de la humanidad sea incierto, entonces posiblemente podríamos construir un 'puente hacia el futuro' [que es el subtítulo de la obra] construyendo la disciplina de la bioética como un puente entre las dos culturas... Los valores éticos no pueden ser separados de los hechos biológicos" (5).

Más adelante, en el Capítulo 1, decía que "la humanidad necesita urgentemente de una nueva sabiduría que le proporcione el 'co- 


\section{Revista Brasileira de Bioética}

nocimiento de cómo usar el conocimiento' para la supervivencia del hombre y la mejora de la calidad de vida" (5). Para esta nueva ciencia, construida sobre la propia biología e incorporando, además, la mayoría de los elementos esenciales de las ciencias sociales y humanísticas, incluyendo la filosofía, propuso Potter el nombre de bioética para resaltar los dos elementos más importantes: el conocimiento biológico (bios) y los valores humanos (ethos).

Para Potter, el significado de la palabra bioética, en 1971, representaba la afirmación de dos conclusiones: en primer lugar, que la supervivencia de un futuro a largo plazo se reduce a una cuestión de bioética, no de una ética tradicional; en segundo lugar que, para ese futuro a largo plazo, había que inventar y desarrollar una política bioética ya que la ética tradicional se refiere a la interacción entre personas, mientras que la bioética implica la interacción entre personas y sistemas biológicos. Por eso, decía Potter en el Prefacio de su obra:

"Necesitamos de una Ética de la Tierra, de una Ética de la Vida Salvaje, de una Ética de Población, de una Ética de Consumo, de una Ética Urbana, de una Ética Internacional, de una Ética Geriátrica etcétera. Todos estos problemas requieren acciones basadas en valores y en hechos biológicos. Todos ellos incluyen la bioética y la supervivencia del ecosistema total constituye la prueba del valor del sistema" (5).

Es el concepto de Bioética Global. Por eso se quejaba Potter de que "la bioética hubiera sido acaparada durante la siguiente década por los 'comités bioéticos' médicos que trabajaban en centros de bioética en el área clínica, tratando problemas de vida y muerte que son todavía controvertidos" (13).

Así, la bioética quedaba restringida a una bioética médica o bioética clínica, como ya puso de manifiesto, en 1975, en su alocución presidencial de la 66 ${ }^{\text {a }}$ Reunión Anual de la Asociación Americana del Cáncer (14). No obstante, también podría argumentarse legítimamente, desde el punto de vista opuesto, que Potter polarizó su idea de la bioética hacia una bioética medioambiental o bioética ecológica. De hecho, su libro está dedicado a Aldo Leopold, ingeniero forestal de la Wisconsin University, quien - en palabras de Potter - con su obra 
Land Ethic (15) "anticipó la extensión de la Ética a la bioética".

Estoy de acuerdo con Potter en que la bioética intenta relacionar nuestra naturaleza biológica y el conocimiento realista del mundo biológico con la formulación de políticas encaminadas a promover el bien social. Por ello, en mi opinión, la bioética puede referirse directamente al hombre mismo - ya sea a nivel individual, de población o de especie - o indirectamente, cuando el problema bioético afecta a su entorno ecológico, tanto si se refiere a los seres vivos (microorganismos, plantas o animales) como a la naturaleza inanimada, aunque esto último parezca un contrasentido. La bioética consiste, por tanto, en el diálogo interdisciplinar entre vida (bios) y valores morales (ethos); es decir, trata de hacer juicios de valor sobre los hechos biológicos, en el sentido más amplio del término, y obrar en consecuencia.

En los más de 36 años transcurridos, la bioética ha crecido de forma espectacular, habiendo llegado a decirse que "la bioética ha salvado a la ética filosófica" (16), que "la bioética será la ética del Siglo XXI" o que, incluso, "el Tercer Milenio será la Era de la Bioética Global o la Era de la Anarquía" (17).

Como él mismo dijo, Potter fue durante 60 años un profesional de la investigación del cáncer y durante 30 años un filósofo biológico amateur. Como señala Abel (18), el trabajo de Potter, en la bioética, pasó desapercibido durante mucho tiempo quizá porque su filosofía ecológica no fue conocida, comprendida o aceptada, aunque en el campo de la bioética medioambiental tiene más de 50 publicaciones. Su preocupación por la Bioética Global le llevó también a Potter (19) al planteamiento de la biocibernética y la supervivencia, entendiendo la biocibernética como "toda interacción biológica que tiene lugar entre el hombre y su entorno" (20).

\section{El Principio de Responsabilidad de Jonas}

Hans Jonas (1903-1993) fue discípulo de los filósofos Husserl y Heidegger y del teólogo Bultmann. Emigró a Israel en 1933, trasladándose a Canadá en 1949 y, posteriormente, a Estados Unidos, en 1955 (New School for Social Research, New York). En la década de los setenta comenzó a interesarse por los problemas éticos que se podían derivar de los avances de la técnica y de la medicina, sin olvidar la 


\section{Revista Brasileira de Bioética}

genética. En las primeras líneas del Prólogo de su obra El principio de responsabilidad. Ensayo de una ética para la civilización tecnológica señala:

"Definitivamente desencadenado, Prometeo, al que la ciencia proporciona fuerzas nunca antes conocidas y la economía un infatigable impulso, está pidiendo una ética que evite mediante frenos voluntarios que su poder lleve a los hombres al desastre. La tesis de partida de este libro es que la promesa de la técnica moderna se ha convertido en una amenaza, o que la amenaza ha quedado indisolublemente asociada a la promesa... Lo que hoy puede hacer el hombre - y después, en el ejercicio insoslayable de ese poder, tiene que seguir haciendo - carece de parangón en la experiencia pasada. Toda la sabiduría anterior sobre la conducta se ajustaba a esa experiencia; ello hace que ninguna de las éticas habidas hasta ahora nos instruya acerca de las reglas de 'bondad' y 'maldad' a las que las modalidades enteramente nuevas del poder y de sus posibles creaciones han de someterse. La tierra virgen de la praxis colectiva en que la alta tecnología nos ha introducido es todavía, para la teoría ética, tierra de nadie... En ese vacío (que es al mismo tiempo el vacío del actual relativismo de los valores) es donde se sitúa esta investigación" (21).

Teniendo en cuenta que el peligro del poder tecnológico y de la acción humana puede servirnos de guía ética para descubrir los principios éticos de los que se derivarán los nuevos deberes del nuevo poder, a lo que Jonas llama heurística del temor, en el Prólogo de su obra:

"Sólo la previsible desfiguración del hombre nos ayuda a alcanzar aquel concepto de hombre que ha de ser preservado de tales peligros. Solamente sabemos qué está en juego cuando sabemos que está en juego. Puesto que lo que aquí está implicado es no sólo la suerte del hombre, sino también el concepto que de él poseemos, no sólo su supervivencia física, sino también la integridad de su esencia, la ética - que tiene que 
custodiar ambas cosas - habrá de ser, trascendiendo la ética de la prudencia, una ética del respeto... el tema propiamente dicho del libro es ese mismo deber recién aparecido que se resume en el concepto de responsabilidad. No se trata ciertamente de un fenómeno nuevo para la moral; no obstante, la responsabilidad nunca antes tuvo un objeto de tal clase y hasta ahora había ocupado poco a la teoría ética. Tanto el saber como el poder eran demasiado limitados como para incluir en su previsión el futuro remoto y para incluir en la conciencia de la propia causalidad el globo terráqueo... Está además la evidente magnitud de los efectos remotos y también, a menudo, su irreversibilidad. Todo ello coloca la responsabilidad en el centro de la ética, dentro de unos horizontes espaciotemporales proporcionados a los actos. Por consiguiente, la teoría de la responsabilidad, inexistente hasta hoy, constituirá el centro de esta obra" (21).

Las preocupaciones de Jonas pueden resumirse en algunos de sus aforismos $(22 ; 23)$ : "Obra de tal modo que los efectos de tu actuación sean compatibles con la permanencia de una vida humana auténtica en la Tierra", que, expresado negativamente, se enuncia como: "Obra de tal modo que los efectos de tu acción no sean destructivos para la futura posibilidad de esa vida", o, simplemente: "No pongas en peligro las condiciones de la continuidad indefinida de la humanidad en la Tierra", que, formulado positivamente, dice: "Incluye en tu elección presente, como objeto también de tu querer, la futura integridad del hombre".

En la comparación que hace el propio Jonas de sus imperativos con el imperativo categórico de Kant - obra de tal modo que puedas querer también que tu máxima se convierta en ley universal - dice que el nuevo imperativo se dirige más a la política pública que al comportamiento privado. El imperativo categórico de Kant estaba dirigido al individuo y su criterio era instantáneo, mientras que el nuevo imperativo de Jonas no apela a la concordancia del acto consigo mismo, sino a la concordancia de sus efectos últimos con la continuidad de la actividad humana en el futuro.

También utiliza Jonas el aforismo in dubio, pro malo, queriendo 


\section{Revista Brasileira de Bioética}

significar que en caso de duda se debe pensar que puede ocurrir lo peor y por tanto abstenerse de llevar a cabo tal acción. Es equivalente al principio de precaución: en la duda, abstente. Por ejemplo, este principio de precaución ha sido fuertemente esgrimido por los grupos ecologistas que se oponen a la utilización de las plantas transgénicas (24).

También Ferrer y Álvarez, en el capítulo de Conclusión de su obra Para fundamentar la bioética, reconociendo la influencia de Hans Jonas y de Diego Gracia, establecen bajo el influjo del imperativo categórico kantiano, que el canon formal de la moralidad, con valor universal, podría formularse así:

"Todos y cada uno de los seres personales actuales merecen igual consideración y respeto (son fines en sí mismos), mientras que los seres humanos de las generaciones futuras, las especies animales, el entorno y la biosfera merecen respeto en su conjunto, aunque individualmente puedan ser tratados como medios (individualmente no pueden ser considerados fines, pero sí globalmente) (25)".

\section{Globalización y medio ambiente}

Así como Potter se centró de forma mayoritaria en los problemas ecológicos y medioambientales, Jonas, en su libro que lleva a la práctica el Principio de responsabilidad (26), abordó más los problemas éticos derivados de los experimentos realizados con sujetos humanos, la biomedicina y la genética que los problemas medioambientales. No obstante, a través de ambos autores se llega a una postura de responsabilidad hacia las futuras generaciones.

Hans Jonas, al considerar las dimensiones globales en el espacio y el tiempo de los avances de la técnica moderna, decía:

"Con lo que hacemos aquí y ahora, la mayoría de las veces pensando en nosotros mismos, influimos masivamente sobre la vida de millones de personas, en otros lugares y en el futuro, que no tienen voz ni voto al respecto. Hipotecamos la vida futura a cambio de ventajas y necesidades a corto plazo... la 
mayoría de las veces, necesidades creadas por nosotros mismos... la categoría ética que este nuevo hecho saca a la palestra se llama responsabilidad" (27).

Esta ética de la responsabilidad es una ética orientada al futuro en el sentido de que "pretende proteger a nuestros descendientes de las consecuencias de nuestras acciones presentes" (27).

En la ciencia jurídica se dice correctamente que lo que no existe no tiene derechos, pero ello no quiere decir que nosotros no tengamos obligaciones y deberes hacia las futuras generaciones. En términos ecológicos y medioambientales deberíamos tener siempre muy presente aquella reflexión que dice que "no hemos heredado la Tierra de nuestros padres, sino que la hemos tomado prestada de nuestros hijos".

La contaminación ambiental, el efecto invernadero, la desertización, la deforestación (por la tala masiva de bosques o por incendios), el agotamiento de los recursos naturales por prácticas contrarias al desarrollo sostenible, los problemas del agua de riego (escasez, salinidad), la falta de agua potable en muchas poblaciones humanas, la contaminación de mares y costas etc, son algunos de los problemas que afectan a la Bioética Global.

En la década de 70 del siglo pasado afloró la preocupación mundial por el peligro ecológico, que Gracia llama revolución ecológica (28). Así, el mismo autor señala la repercusión que tuvieron el Informe del Club de Roma de 1972 (The limits of growth), el Informe 2000 que se elaboró en Estados Unidos de América durante la presidencia de Jimmy Carter y el informe Our common future, elaborado en 1987 por la Comisión Mundial del Medio Ambiente y del Desarrollo de las Naciones Unidas.

En este contexto tienen especial relevancia algunos encuentros internacionales en los temas relacionados con la biodiversidad (Cumbre de Río de Janeiro, 1992), la bioseguridad (Cartagena, Colombia, 1999; Montreal, 2000) y la contaminación atmosférica (Convención Marco de Naciones Unidas sobre el Cambio Climático, Nueva York, 1992, cuyo Protocolo fue aprobado en Kyoto, Japón, en 1998).

Por ello, hago mías las palabras que, hace ya muchos años, escuché al profesor Juan Oró: 


\section{Revista Brasileira de Bioética}

"Pido a la tecnología moderna la facilidad de intercomunicarme con mis semejantes sin que el ruido de los aviones me enloquezca ni las radiaciones maten mis células. Pido utilizar la energía fósil sin que la contaminación devaste nuestras costas, o la energía nuclear sin que ello produzca en mis descendientes anomalías genéticas eternas".

A estas peticiones podríamos añadir la que en cierta ocasión escribí en relación con las plantas transgénicas: "Pido utilizar la biotecnología de la agricultura transgénica sin que ello perjudique nuestro entorno ecológico ni atente contra la salud del mundo" (29).

\section{Globalización, sociedad y política}

Como señala González-Carvajal, no hay que confundir globalización con mundialización (30). En efecto, la mundialización es el fenómeno por el cual están desapareciendo las barreras culturales, geográficas y políticas en nuestro Planeta. Es la unificación del planeta Tierra: la aldea global. En contraparte, la globalización, en la práctica, significa capitalismo global. Podemos utilizar algunos ejemplos:

- Internacionalización del comercio, como se pone de manifiesto en la existencia de la Organización Mundial del Comercio (OMC).

- Internacionalización de la producción: por ejemplo, un automóvil puede estar compuesto por piezas fabricadas en 112 lugares distintos, distribuidos por 16 países, pertenecientes a tres continentes.

- Internacionalización de los capitales: por ejemplo, basta pulsar una orden en una tecla de un ordenador para que un depósito de miles de millones de dólares situado en un momento dado en Hong Kong, pase en un minuto a estar depositado en otro banco de Nueva York y, pulsando otra tecla, al minuto siguiente en Londres. Son los "capitales golondrina".

- Una economía sin fronteras: el escenario económico ha dejado de ser local y nacional, pasando a ser internacional. La consecuencia es que la vida de las personas que viven en un 
punto determinado del planeta se ve afectada por las decisiones que se toman en lugares muy alejados.

En muchas ocasiones, sin embargo, el término globalización ha perdido su significado estrictamente económico del término, utilizándose en otros contextos diferentes; por ejemplo: 1) La globalización de las comunicaciones conduce inevitablemente a la globalización de los problemas y sus posibles soluciones, aunque aquellos puedan ser de distintas naturalezas y estén influenciados por culturas diferentes; 2) Los problemas bioéticos de la biomedicina están globalizados. Sin embargo, ¿̇es posible aplicarles una Bioética Global en el sentido de universal?

\section{Bioética y política: la opinión pública y la opinión publicada}

Se ha dicho muchas veces que no hay que confundir la opinión pública con la opinión publicada puesto que frecuentemente los medios de comunicación se empeñan en hacernos creer que lo que ellos opinan es lo que opina la sociedad. En numerosas ocasiones he dicho que no sólo hay que hablar de manipulación genética, sino también de la manipulación social que puede haber tras ella. Por ello, en debates como el de la utilización de las células troncales embrionarias o el de la selección de embriones en las técnicas de fecundación in vitro, es importante saber cuál es la opinión de la sociedad en su conjunto y constatar el grado de comprensión que el ciudadano medio tiene de los temas sobre los que da su opinión, a lo mejor (o a lo peor) sin tener un criterio sólido.

La Declaración Universal sobre el Genoma Humano y los Derechos Humanos de la UNESCO, firmada en 1997, hace en varios artículos un llamamiento a la educación de la sociedad en relación con las investigaciones genéticas, biológicas y médicas. Así...

"Artículo 20.

Los Estados tomarán las medidas adecuadas para fomentar los principios establecidos en la Declaración, a través de la educación y otros medios pertinentes, y en particular, entre otras cosas, la investigación y formación en campos interdisci- 
plinarios y el fomento de la educación en materia de bioética, en todos los niveles, particularmente para los responsables de las políticas científicas.

Artículo 21.

Los Estados tomarán las medidas adecuadas para fomentar otras formas de investigación, formación y difusión de la información que permitan a la sociedad y a cada uno de sus miembros cobrar mayor conciencia de sus responsabilidades ante las cuestiones fundamentales relacionadas con la defensa de la dignidad humana que puedan plantear la investigación en biología, genética y medicina y las correspondientes aplicaciones. Se deberían comprometer, además, a favorecer al respecto un debate abierto en el plano internacional que garantice la libre expresión de las distintas corrientes de pensamiento socioculturales, religiosas y filosóficas" [en ambos la cursiva es mía].

\section{La opinión pública europea y la biotecnología: dos encuestas}

En relación con la opinión pública, puede ser interesante hacer alusión a los datos de sendas encuestas realizadas en 2003 y 2005 entre los ciudadanos europeos en relación con la biotecnología: el Estudio Europeo de Biotecnología de la Fundación sediada en España del Banco Bilbao Vizcaya Argentaria (BBVA) $(31 ; 32 ; 33 ; 34)$ y el informe derivado de estudio que se llamo Europeos y Biotecnología en 2005: Modelos y tendencias, conocido como Eurobarómetro 64.3.

\section{Estudio Europeo de Biotecnología de la Fundación BBVA de España}

El 30 de julio de 2003, la Unidad de Estudios de Opinión Pública de la Fundación BBVA, de España, hizo público su Estudio Europeo de Biotecnología que es su primer análisis de percepciones y actitudes hacia la biotecnología en nueve países europeos: España, Alemania, Reino Unido, Francia, Italia, Holanda, Austria, Polonia y Dinamarca. La encuesta (con una duración del cuestionario de una hora) - que se realizó entre octubre de 2002 y febrero de 2003 - se hizo sobre una muestra de 1.500 personas mayores de 18 años en cada uno de los 
nueve países (13.500 encuestas en total), con una técnica de muestreo basada en rutas aleatorias y representativas del conjunto.

Lo que la encuesta de la Fundación BBVA hace es poner de manifiesto cuál es en nueve países de Europa - seleccionados atendiendo a su peso demográfico y a la variedad de las creencias religiosas - la percepción y actitud de los ciudadanos sobre temas importantes en la actualidad como por ejemplo, como es la manipulación de embriones humanos, ya sea para utilizar sus células troncales pluripotentes para establecer cultivos de tejidos con una posible aplicación en la medicina regenerativa ya sea para hacer un diagnóstico genético preimplantatorio dentro de los programas de fecundación in vitro (FIV). Algunos de los datos recogidos en la encuesta son presentados a seguir.

\section{La investigación con células troncales y su aplicación en la tera- pia celular de la medicina regenerativa del futuro}

Para abordar la cuestión de la utilización de las células troncales en la terapia celular de la medicina regenerativa, la encuesta europea de la Fundación BBVA plantea implícitamente el problema de los fines y los medios: el fin médico es fantástico, pero a costo de la utilización de embriones humanos; es decir, en los dos platillos de la balanza están los beneficios médicos futuros frente a los derechos de los embriones. La encuesta pregunta la opinión sobre dos planteamientos muy relacionados entre sí, que se indican a continuación:

- Cuestión 1ª: "Los beneficios médicos para muchos seres humanos, que quizás pueden alcanzarse en el futuro gracias a la investigación con embriones de poco días, son mucho más importantes que los derechos de los embriones".

- Cuestión 2a. "Debería apoyarse la investigación con células troncales de embriones de pocos días para tratar de encontrar, cuanto antes, curas eficaces de enfermedades como el Parkinson, el Alzheimer o la diabetes".

La valoración de la contestación oscila entre 0 y 10, donde 0 indica completo desacuerdo y 10 completo acuerdo con la cuestión planteada. La respuesta a la primera cuestión es muy homogénea en los nueve países, con cinco países que se inclinan a favor del embrión y 


\section{Revista Brasileira de Bioética}

cuatro a favor de la aplicación médica (entre ellos España, con 5,3) aunque, en cualquier caso, con valores próximos a un valor medio de 5 sobre 10 .

En relación con la siguiente, todos los países se inclinan a favor de la utilización de las células troncales embrionarias para tratar de curar determinadas enfermedades. Lo que resulta sorprendente, y a mi juicio en cierta manera incongruente, es que, excepto Austria, todos los países incrementan su valoración media entre uno o dos puntos cuando esta segunda cuestión perjudica al embrión frente al progreso de la medicina y, por tanto, debería coincidir sustancialmente con los resultados de las respuestas a la cuestión $1^{\mathrm{a}}$. El valor medio de los encuestados españoles es de 6,3 frente al valor máximo de Francia $(7,0)$ y el más bajo de Austria $(4,4)$ y Alemania $(5,0)$.

Ante estas situaciones de aparente contradicción, habría que plantearse cuál es el grado de información y conocimiento reales que tienen los encuestados sobre los temas implicados. Esto es lo que la Euroencuesta planteó respecto a las información recibida y la comprensión por parte de los encuestados de lo que significa "utilización de células troncales embrionarias" en términos bioéticos. Así, en primer lugar, se le preguntó a cada ciudadano encuestado si "ha leído, escuchado o visto alguna información sobre células troncales" $y_{\text {, en }}$ segundo lugar, si "comprende lo que significan las células troncales; es decir, que, cumpliendo la condición de la pregunta anterior, sabe que su uso implica la destrucción del embrión".

De los resultados obtenidos, se deduce que España ocupa una posición intermedia en el escenario europeo, siendo una tónica general en los nueve países que una cosa es que los ciudadanos hayan oído hablar con mayor o menor intensidad de la problemática de las células troncales (desde el 68,1\% de Italia al 28\% de Polonia) y, otra, que el ciudadano que ha sido "bombardeado" con dicha información comprenda que para utilizar esas células troncales es preciso destruir el embrión en estadio de blastocisto. En este caso, Alemania ocupa el primer lugar $(28,4 \%)$ y Polonia, de nuevo, el último $(8,2 \%)$.

En España, donde más de la mitad de los encuestados $(54,1 \%)$ ha oído hablar del tema, solamente menos de la tercera parte (el 16,5\%) comprende la necesidad de destrucción del embrión para utilizar las células troncales pluripotentes. ¿Cómo se puede tomar partido res- 
ponsablemente a favor o en contra de tales técnicas sin saber exactamente de lo que se trata? Esta incongruente situación es general en los otros ocho países europeos encuestados, porque los ciudadanos verdaderamente informados oscilan entre la cuarta y la tercera parte de los que han tenido algún tipo de información. El país "más culto" en relación con el tema es Alemania, porque algo más del $40 \%$ de los informados comprende de qué se trata. En cualquier caso, como concluye el informe del Fundación BBVA,

“... una primera cuestión importante a resaltar es que, a pesar de la insistencia con que se trata en los medios de comunicación social, el tema de las células troncales y su posible aplicación en la medicina regenerativa del futuro, el conocimiento existente en Europa acerca de las células troncales es sumamente bajo" (31).

Dado el bajo nivel de conocimientos existente en Europa acerca de las células troncales, la Fundación BBVA llega a la conclusión de que "las percepciones de la mayor parte de la población adulta hacia la investigación con embriones se fundamenta no tanto en conocimientos específicos, sino sobre todo en valores, imágenes, criterios morales y creencias religiosas" (31).

\section{Visiones sobre la condición moral del embrión y el comienzo de la vida humana individual}

Las células troncales embrionarias se pueden obtener de la masa celular interna (MCI) de embriones (blastocistos) producidos por fecundación in vitro (FIV) con el único propósito de obtener cultivos de tejidos, o de la MCI de embriones sobrantes de programas de FIV con fines reproductivos.

Como señala la encuesta de la Fundación BBVA, en los nueve países europeos hay dos percepciones claramente diferenciadas respecto a la experimentación con embriones humanos, expresamente obtenidos por FIV con dicho fin o con embriones sobrantes procedentes de un programa de reproducción asistida mediante FIV y transferencia embrionaria (FIVETE). Las cuestiones que se planteaban en la encuesta eran las siguientes: 


\section{Revista Brasileira de Bioética}

- ¿Es moralmente aceptable en el caso de embriones sobrantes de los tratamientos de reproducción asistida, esto es, de embriones que nunca van a desarrollarse?

- $i$ Es moralmente aceptable en el caso de embriones de unos pocos días creados específicamente para hacer avanzar la investigación?

Los valores medios son obtenidos en una escala de 0 a 10 , donde 0 indica completamente inaceptable y 10 completamente aceptable. La investigación con embriones sobrantes recibe el apoyo mayor en Dinamarca $(6,7)$ y Francia $(6,1)$ y el mayor rechazo en Austria $(3,6)$. En España, el valor medio es de 5,6. Llama la atención que en el Reino Unido, que es un país en el que está legalmente autorizada la obtención de embriones con fines exclusivos de investigación, la opinión de la población según la encuesta sea de rechazo a la misma (valor medio 4,4).

Como comenta el informe de la Fundación BBVA, hay países en los que existen segmentos importantes de población que carecen de una posición definida; como por ejemplo, Polonia (con un 27\% sin opinión), España (22\%), Austria (21\%), el Reino Unido (20\%) e Italia (17\%), mientras que en otros países, como Dinamarca, Alemania, Francia y Holanda, las posiciones están bien definidas (valores comprendidos entre el 2,5 y el 9,1\%) aunque su contenido sea distinto.

Por otro lado, el informe concluye que el uso de embriones creados específicamente para la investigación, es rechazado en la actualidad por la mayoría relativa de la población de las sociedades europeas consideradas aquí, con la excepción de Dinamarca, donde se obtiene una aprobación con una media de 5,7. Ese nivel de rechazo es particularmente fuerte en Austria (media de 2,7) y en Alemania $(2,8)$. En España - con un valor medio de rechazo de 4,7 - un 29,7\% rechaza claramente la creación de embriones (valor entre 0 y 3), un $25,3 \%$ la aprueba (valor entre 7 y 10 ), un $23,3 \%$ se sitúa en posiciones intermedias (valor entre 4 y 6) y casi un 21,7\% no tiene una opinión formada.

Como señala el Informe de la Fundación BBVA, sobre la valoración moral de la utilización de las células troncales embrionarias humanas entran en juego dos marcos conceptuales particularmente 
relevantes, puesto que la utilización de las células troncales implica la destrucción de los embriones:

- Las percepciones sobre la condición moral del embrión que, en el momento actual, van desde su consideración como "un conjunto de células sin condición moral" hasta su consideración como portador de la "misma condición moral que un ser humano". Se trata, en definitiva, del denominado Estatuto del Embrión cuyo análisis completo debería ser abordado desde los puntos de vista biológico, ontológico, ético, jurídico y teológico.

- El debate sobre la condición moral del embrión es, en términos de la opinión pública, relativamente reciente. Otro marco conceptual, relacionado con el anterior y más arraigado en las percepciones de los individuos, es el de la imagen del momento en que comienza la vida humana individual equiparable con el ser humano, abarcando desde quienes creen que el momento de comienzo de la vida coincide plenamente con "la unión del óvulo y el espermatozoide" (fecundación) hasta los que piensan que comienza sólo "con el nacimiento de un nuevo individuo".

Ambos planteamientos conceptuales fueron planteados en la encuesta, desglosando los valores totales teniendo en cuenta la profesión religiosa ("creyentes" o "no creyentes") de los encuestados. De los resultados obtenidos, el informe de la Fundación BBVA concluye que la investigación con células troncales afecta la dimensión moral o ética de cada individuo y los criterios morales de inspiración religiosa constituyen un factor clave para comprender las posturas existentes hoy en Europa.

\section{Valoración del test genético preimplantatorio: selección de embriones}

No cabe duda que la fecundación in vitro (FIV) es un avance clínico importante para la sociedad moderna, porque contribuye a remediar muchos de los casos de infertilidad que con tan alta frecuencia se dan entre las parejas humanas. Siguiendo la máxima de que "a nue- 


\section{Revista Brasileira de Bioética}

vos progresos científicos, nuevos retos éticos", la FIV plantea una serie de problemas bioéticos importantes, como son la experimentación con embriones sobrantes (que ha sido tratada en el apartado anterior) o la selección de embriones tras un diagnóstico preimplantatorio. Respecto a la opinión sobre la realización del diagnóstico preimplantatorio en un programa de FIV, se consideraron las tres situaciones siguientes:

- para saber si el futuro niño o niña puede padecer alguna enfermedad genética grave y en ese caso evitar su implantación y desarrollo en el útero;

- para que una pareja con enfermedades genéticas pueda saber se el hijo o hija tendrán la misma enfermedad y, en su caso, no seguir adelante con su implantación;

- para conocer el sexo de los hijos y, si no coincidiera con el sexo que se quiere tener, poder decidir que el embrión no se implante en el útero de la madre.

Los valores obtenidos muestran que la mayoría de los países europeos encuestados acepta sin reservas las dos primeras cuestiones; es decir, la selección de embriones para evitar taras genéticas en la descendencia con valores bastante altos, superando los 7 puntos en la mayor parte de los países, mientras que de forma unánime se rechaza la selección de embriones por razón del sexo, oscilando los valores medios entre 1,2 y 2,7 (recuérdese que el valor 0 indica total desacuerdo y 10 total acuerdo con la propuesta).

Las respuestas respecto a la selección o eliminación de los embriones obtenidos por FIV "por causas genéticas justificadas" son coherentes con la valoración moral que los encuestados hacen sobre el embrión en sus primeras fases de desarrollo (embrión preimplantatorio), tal como se ha comentado anteriormente. En cualquier caso, es importante desde el punto de vista bioético destacar que un proceso de selección de embriones implica la eliminación de otros.

La encuesta de la Fundación BBVA contribuyó sin duda alguna a conocer el "estado de la cuestión" en la sociedad española dentro del contexto europeo, permitiéndonos saber cuál es verdaderamente la opinión pública sobre estos temas y evitando la manipulación que 
a veces supone la "opinión publicada". En definitiva, se estaría actuando conforme indicaba la UNESCO en su Declaración Universal de 1997, a la que antes se hacía referencia.

\section{El Eurobarómetro 2005}

En mayo de 2006 se hiz

o público el informe elevado a la Dirección General para la Investigación de la Comisión Europea titulado Europeos y Biotecnología en 2005: Modelos y Tendencias y conocido como Eurobarómetro 64.3. El informe (35) fue coordinado por George Gaskell, vice-director del Centro para el Estudio de Biociencia, Biomedicina, Biotecnología y Sociedad (BIOS), London School of Economics. Este Eurobarómetro, que es el sexto de una serie de eurobarómetros sobre biotecnología (1991, 1993, 1996, 1999, 2002 y 2005), está basado en una encuesta realizada en 2005 a una muestra representativa de 1.000 ciudadanos de cada uno de los 25 países que entonces integraban la Unión Europea.

Los temas que se tratan en el Eurobarómetro son: 1) Incidencia futura de la biotecnología en la sociedad; 2) Evaluación de las aplicaciones de la biotecnología (terapia génica, farmacogenómica, alimentos transgénicos, nanotecnología, biotecnología industrial); 3) Investigación con células troncales; 4) Gobernanza, confianza e información en ciencia y tecnología; 5) Compromiso y conocimiento; 6) Juventud y ciencia: la Europa de mañana; 7) La mujer y la ciencia; 8) Comparación transatlántica (Estados Unidos y Canadá). Por razones del espacio, a continuación solamente se incluye un resumen global de los resultados obtenidos en la encuesta, aun que comentario detallado de la misma fue realizado por el autor (36):

- En comparación con los eurobarómetros anteriores, los ciudadanos europeos se muestran más optimistas sobre la tecnología en general y se consideran mejor informados y tienen más confianza en la biotecnología. Así como durante el período 1991-1999 la opinión de los europeos sobre la biotecnología decreció paulatinamente, en el período 1999-2005 ha vuelto a mostrar una tendencia positiva, alcanzando los niveles de 1991. 


\section{Revista Brasileira de Bioética}

- Aunque la mayoría de los europeos prefiere delegar a los expertos la responsabilidad sobre las nuevas tecnologías, tomando las decisiones sobre bases científicas, sin embargo, una minoría importante preferiría que se diera más peso a las consideraciones éticas y morales y a la opinión pública en la toma de decisiones sobre ciencia y tecnología.

- Hay un amplio apoyo a la biotecnología médica (también llamada biotecnología roja) y a la biotecnología industrial (blanca) mientras que hay un rechazo general a la biotecnología agrícola (verde), en tanto en cuanto no se demuestre que es beneficiosa para el consumidor. Sin embargo, no hay evidencia de que su rechazo a los alimentos transgénicos sea una manifestación de un mayor desencanto sobre la ciencia y la tecnología en general.

- La visión utilitarista de los europeos se manifiesta, por ejemplo, en que su apoyo a la investigación con células troncales se basa en el binomio riesgo-beneficio.

- Respecto a la nanotecnología, la farmacogenómica y la terapia génica, la percepción de los europeos es que consideran a las tres tecnologías útiles para la sociedad y moralmente aceptables, concordando que el riesgo que pueda implicar la terapia génica es asumible dada su utilidad y que no comporta problemas morales.

- En su conjunto, los europeos opinan que no se deberían promocionar los alimentos transgénicos porque los consideran innecesarios, moralmente inaceptables y como un riesgo para la sociedad. Sin embargo, en los países en los que los ciudadanos dicen tener un criterio claramente establecido, los partidarios y oponentes a los alimentos transgénicos suponen un 58\% y un $42 \%$, respectivamente. Solamente en España, Portugal, Irlanda, Italia, Malta, República Checa y Lituania los ciudadanos que están a favor de los alimentos transgénicos superan en número a los que se oponen a ellos. La decisión de comprar o no comprar alimentos transgénicos se basa más en razones de salud, reducción de residuos de pesticidas e impacto medioambiental, que en su menor costo o en que sean autorizados por la autoridad correspondiente.

- Los ciudadanos europeos apoyan ampliamente las biotecnologías industriales o biotecnologías blancas, como son la obtención de bio-fuel (biocombustibles o combustibles renovables), bio-plásticos 
(biodegradables) y bio-plantas (medicamentos de origen vegetal), aunque muchos no dicen si estarían dispuestos a pagar más por un vehículo que funcionara con bio-fuel o por los bio-plásticos. Teniendo en cuenta el rechazo de los alimentos transgénicos y, por tanto, de las plantas transgénicas que los producen, resulta llamativo que, sin embargo, un $60 \%$ de los ciudadanos encuestados aceptarían las plantas transgénicas con fines no alimentarios si se regulan estrictamente. En todos los países de Europa, excepto en Austria, los partidarios de las bio-plantas superan en número a los que se oponen a ellas.

- En relación con la investigación con células troncales, de forma global los europeos se inclinan a favor de las células troncales adultas (65\%) frente al 59\% que se inclinan hacia la utilización de las células troncales embrionarias. Los países que más apoyan a estas últimas son Bélgica, Suecia, Dinamarca, Holanda e Italia. Europa se encuentra muy dividida en cuanto a la utilización de argumentos no contingentes, deontológicos y morales frente a las posturas contingentes y utilitarias, inclinándose hacia una visión contingente del problema: los posibles beneficios para la salud.

- Al preguntar a los ciudadanos qué les gustaría saber sobre las células troncales si se les consultara en un referéndum, respondieron que no les interesaban los datos científicos, sino más bien las consecuencias sociales - los riesgos y beneficios - que tal investigación comportara a la sociedad, por un lado, y si la regulación y el control ético son los adecuados, por otro lado.

- Para sacar conclusiones acerca del gobierno de la ciencia y la tecnología - es decir, quién debe tomar las decisiones y según qué criterios - se plantearon cuatro principios de gobernanza, combinando dos a dos las siguientes opciones: criterio de los expertos (A) versus opinión pública (B) y evidencia científica sobre riesgos y beneficios (C) versus consideraciones éticas y morales (D). Los principios de gobernanza así definidos, son el de "delegación científica" (A y C), "delegación moral" (A y D), "deliberación científica" (B y C) y "deliberación moral" (B y D). En la encuesta global, los europeos se inclinaban según los mencionados principios en un 59\%, 17\%, 9\% y $15 \%$, respectivamente. En otras palabras, uno de cada tres europeos (A y $\mathrm{D}+\mathrm{B}$ y $\mathrm{D}=32 \%$ ) dan más importancia a los temas éticos que a los científicos y uno cada cuatro (B y C + B y D $=24 \%$ ) prefieren la de- 


\section{Revista Brasileira de Bioética}

cisiones basadas en la opinión pública (deliberación) más que en los expertos (delegación).

- Respecto al uso de la información genética privada, un 58\% de los europeos autorizarían que sus datos genéticos fueran incorporados a un banco de datos con fines de investigación, frente a un 36\% en contra. El uso comercial (por ejemplo, en compañías de seguros) se considera inaceptable de forma muy mayoritaria.

Ponencia presentada en el $5^{\circ}$ Congreso de Bioética de América Latina y el Caribe, Federación Latinoamericana y del Caribe de Instituciones de bioética (FELAIBE), que tuvo lugar en la Ciudad de Panamá, Panamá, del 9 al 13 de agosto de 2005.

\section{Referencias}

1. Lacadena JR. Genética y bioética (Cap. 1). Madrid: Universidad Pontificia Comillas; Bilbao: Editorial Desclée de Brouwer; 2002.

2. Dobzhansky T. Evolution of mankind. In: Dobzhansky T Ayala FJ Stebbins GL \& Valentine JW. Evolution. San Francisco: WH Freeman and Company; 1977, pp. 438-63.

3. Waddington $\mathrm{CH}$. The ethical animal. London: Allen and Unwin; 1960.

4. Dobzhansky T. Op. cit.

5. Potter VR. Bioethics: bridge to the future. New Jersey: Prentice-Hall Inc/ Englewood Cliffs; 1971.

6. Potter VR. Global Bioethics. Building on the Leopold legacy. USA: Michigan State University Press; 1988.

7. Jonas H. Das Prinzip Verantwortung. Francfurt am Main: Insel Verlag; 1979 .

8. Jonas H. Technik, Medizin und Ethik. Zur Praxis des Prinzips Verantwortung. Franfurt am Main: Insel Verlag; 1985.

9. Potter VR. Bioethics, the science of survival. Perspectives in Biology and Medicine 1970; 14: 127-53.

10. Potter VR. Op. cit. 1971.

11. Lacadena JR. Bioética global, una visión global de la bioética y manipulación genética. Revista Latinoamericana de Bioética 2002; 2: 22-53.

12. Lacadena JR. Van Rensselaer Potter: orígenes de la bioética. Jano: Medicina y Humanidades 2002; vol. LXII (1424): 64-5.

13. Potter VR. Opening lecture. In: Ponencias - I Congreso Mundial de Bioética / Sociedad Internacional de Bioética (SIBI); 2000, Gijón, España, pp. 15-8.

14. Potter VR. Humility and Responsibility. Bioethics for Oncologists: Presidential Address 66th Annual Meeting of the American Association of Cancer 
Research, Cancer Research 1975; 35:2297-306.

15. Leopold A. The land ethic: Sand County Almanac, with other essays on conservation from Round River. Oxford: Oxford University Press; 1949.

16. Toulmin S. How medicine saved the life of ethics. Perspectives in Biology and Medicine 1982; 25:736-50

17. Potter VR. Op. cit. 2000.

18. Abel F. Bioética: orígenes, presente y futuro. Barcelona: Instituto Borja de Bioética; Madrid: Fundación Mapfre; 2001.

19. Potter VR. Biocibernética y supervivencia. In: Palacios M (coord.). Bioética 2000. Oviedo: Ediciones Nobel; 2000, pp. 59-78.

20. Potter VR. Op. cit. 1971.

21. Jonas H. Op. cit. 1979.

22. Jonas H. Op. cit. 1979.

23. Jonas H. Op. cit. 1985.

24. Lacadena JR. Agricultura transgénica. In: Villanúa L (coord.) La salud, prioridad en el VI Programa de Medio Ambiente de la Unión Europea, Madrid: Monografía XI, Real Academia Nacional de Farmacia; 2002, pp. 30540.

25. Ferrer JJ \& Álvarez JC. Para fundamentar la bioética. Teorías y paradigmas teóricos en la bioética contemporánea. Madrid: Universidad Pontificia Comillas; Bilbao: Editorial Desclée de Brouwer; 2003.

26. Jonas H. Op. cit. 1985.

27. Jonas H. Op. cit. 1985 (p. 35 de la traducción española).

28. Gracia D. Fundamentación y enseñanza de la bioética. Ética y vida 1, Bogotá: Editorial El Buho Ltda.; 1998, pp. 12-3.

29. Lacadena JR. Op. cit. 2002.

30. González-Carvajal L. 2000. Los cristianos del siglo XXI. Santander: Editorial Sal Terrae; 2000.

31. Fundación BBVA, Unidad de Estudios de Opinión Pública. Estudio Europeo de Biotecnología; 2003.

32. Lacadena JR. La percepción europea y la realidad española sobre la experimentación con embriones humanos: a propósito de la euro-encuesta de la Fundación BBVA y la ley española de modificación de la Ley sobre Técnicas de Reproducción Asistida. In: (F.J. Alarcos, ed.) La moral cristiana como propuesta. Homenaje al profesor Eduardo López Azpitarte. Madrid: San Pablo; 2004, pp.431-60.

33. Lacadena JR. La opinión de los españoles sobre la experimentación con embriones humanos en el contexto europeo. http://w3.cnice.mec.es/tematicas/genetica Noviembre, 2003.

34. Lacadena JR. La opinión de los españoles sobre la Ciencia y la Biotecnología en el contexto europeo. http://w3.cnice.mec.es/tematicas/genetica Diciembre, 2003.

35. Gaskell G; Allansdottir A; Allum N; Corchero C; Fischler C; Hampel J. et 


\section{Revista Brasileira de Bioética}

al. 2006. Europeans and biotechnology in 2005: patterns and trends. Eurobarometer 64.3. A report to the European Commission 's Directorate-General for Research; 2006.

36. Lacadena JR. Europeos y Biotecnología: El Eurobarómetro 2005. http:// w3.cnice.mec.es/tematicas/genetica Julio, 2006.

Recebido em: 13/3/2007 Aprovado em: 29/3/2007 